\title{
Asia on the rise
}

\author{
The balance of scientific power is moving east as scientists in the Asia-Pacific region learn to collaborate \\ more effectively.
}

arlier this month, the Tokyo-based Asia-Pacific arm of Nature

- Publishing Group, which publishes this journal, celebrated its twentieth anniversary by assembling 200 of the region's leading scientists to discuss scientific networking.

Ryoji Noyori, president of RIKEN, Japan's largest research institute, who won the 2001 Nobel Prize in Chemistry for his work on catalysing certain forms of chiral molecules, nicely summed up the thrust of the event: "Asians must be aware that there should be three players: America, Europe and Asia."

There can be no doubt that this mentality - the sense that Asian science exists as a meaningful entity, absorbing contributions not just from Japan, China, Korea and southeast Asia, but also from India, Australia and elsewhere - is slowly gaining acceptance.

But what shape will a more unified concept of Asian science eventually take? It will clearly be a mammoth enterprise, capturing the scientific aspirations of half of the world's population. It will coexist with fraught political relationships: Japan, China and South Korea, for example, remain in conflict over interpretations of responsibility for past wars and ownership of territory. Taiwanese scientists have difficulty travelling to the Chinese mainland and are sometimes left out of scientific meetings. Singapore and Malaysia are often at loggerheads over water supply. The list goes on; by comparison, disagreements between Europe's scientific powers are mere schoolyard spats.

An Asian research community worthy of the name would be a formidable entity. And Asia-Pacific researchers have steadily increased their share of the scientific papers monitored by ISI, the Philadelphiabased citation service, from fewer than $15 \%$ in 1990 to $25 \%$ in 2006.

They are particularly strong in the physical sciences. In terms of the raw volume of physics papers published in ISI-tracked journals, for example, the region is neck-and-neck with the United States, and slightly behind Europe. In chemistry, it is level with Europe and far ahead of the United States. In engineering, all three regions are in a dead heat, and in photonics, Asia has a commanding lead. In nanoscience and materials, the region accounts for nearly as much as the United States and Europe combined. It is true that the average paper from the Asia-Pacific region is cited less often in the literature - but this performance gap is shrinking rapidly.

Changes in Nature Publishing Group's presence in the region reflect this growth. There were four employees in its Tokyo offices in 1990; today there are more than 50 in a region that accounts for about one in six of Nature's global subscriptions. Nature Photonics has its editor-in-chief based in Tokyo and Nature Nanotechnology has a manuscript editor there. Among many regional activities, the Nature China website, launched this month, serves to highlight the nation's hottest research findings. All this expansion reflects the growing role of the region in the world of science.

But that growth places an onus on Asian researchers to look on each other as viable collaborators - something they have not always done in the past. Edison Liu, head of the Genome Institute of Singapore, told the anniversary forum that scientists in the region often maintain a 'West-first' approach to collaboration.

There are several deep-seated reasons for this, including strong academic ties to places where the scientists were often trained, in Europe and North America. Western funding bodies, such as the US National Institutes of Health, the Pasteur Institute and the Wellcome Trust, have been more international in their outlook than their peers in Asia have managed to be.

The customary allure of prestige also plays a role: "A collaboration with Boston is more likely to get you noticed by your chair" than one with a partner closer at hand, Liu says. And researchers in Beijing are more likely to be aware of what is happening in Boston than in Tokyo or, for that matter, in Guangzhou.

One proactive step that many scientists in the region could take would be to make themselves more visible on the Internet. Many still don't have their own homepages, and for those that do, basic contact information and research descriptions are often missing or out of date. This is true even of scientists in Japan and Korea - two of the most 'wired' nations on Earth.

The problem is sometimes exacerbated by the commonness of some family names. Around one-fifth of Koreans have the last
"Areas of common interest, such as global warming, will serve to pull Asian scientists more closely together." name Kim, for example. In recognition of the same problem in China, where 1.3 billion people carry only about 100 family names, the government is considering measures to get people to adopt the practice of taking their mother's name as well as their father's.

On a larger scale, researchers need to work hard to circumvent political tensions and establish regional institutions of genuine quality. Some are already emerging, such as the Asia-Pacific International Molecular Biology Network. But according to one survey of global scientists, far fewer have heard of it than of the European Molecular Biology Organization.

There have already been collaborative successes: the Pan-Asian SNP Initiative, for example, brought together scientists from 11 countries, with diverse resource levels, to analyse genome variations and map out human migration patterns across the continent.

Other areas of common interest, such as global warming, will serve to pull Asian scientists more closely together. At a meeting of the science ministers of South Korea, Japan and China in Seoul in January, energy, bioinformatics, disaster prevention and mitigation, and traditional medicine were identified as holding promise for collaboration.

If these three countries can manage to pull together, they will serve as a powerful anchor for collaboration throughout the wider region. This is certain to broaden and deepen in future, benefiting researchers who have much to gain from getting to know their neighbours. 